\title{
Effect of Boric Acid on the Properties of Sorbitol Plasticized Starch/PVA Blends
}

\author{
Md. Abdul Kader ${ }^{1 *}$, Mubarak A Khan ${ }^{2}$, Md. Elias Molla ${ }^{3}$ \\ ${ }^{1}$ Ahsanullah University of Science and Technology, BANGLADESH \\ ${ }^{2}$ Institute of Radiation and Polymer Technology, Bangladesh Atomic Energy Commission, BANGLADESH \\ ${ }^{3}$ Department of Chemistry, Jahangirnagar University, BANGLADESH \\ ${ }^{*}$ Corresponding Contact: \\ Email: makbiopoly@gmail.com
}

\begin{abstract}
This research aimed to focus on the thermochemical and physico-mechanical properties along with biodegradability nature of partially pregelatinized maize starch (PMS) and polyvinyl alcohol (PVA) based biocomposites. Several PMS/PVA/BA (varying the mass ratio, wt \%) based biocomposites were prepared by solution casting with and without sorbitol plasticizer. Boric acid (BA) used as cross linked agent. The FT-IR, DSC and TGA results revealed that the hydrogen bonding takes place between PMS and PVA in presence of BA and thus biocomposites shown more thermal stability than that of pure PMS and PVA provided by TGA and DSC. Based on the results, sorbitol plasticized PMS/PVA/BA (5\%) was optimized as pliable and stable biocomposite; the tensile strength (TS)and percentage of elongation at break (EB\%) was $16.6 \mathrm{MPa}$ and $11.2 \%$ respectively. However, unplasticized biocomposites shown the highest TS (38.1 MPa) but were hard and brittle. Moreover, the optimized biocomposite was the lower moisture sensitivity and moderate water solubility compared to other biocomposites. In addition, the biodegradability nature of biocomposites were also investigated and found it biodegradable. Thus, the optimized biocomposite (PMS: PVA: BA with a ratio of 40:55:5) can be used as effective and eco-friendly packaging material.
\end{abstract}

Key words

Biocomposite, Biodegradation, Pregelatinized Maize Starch, PVA

$12 / 30 / 2017$

Source of Support: None, NoConflict of Interest: Declared

This article is licensed under a Creative Commons Attribution-NonCommercial 4.0 International License.

Attribution-NonCommercial (CC BY-NC) license lets others remix, tweak, and build upon work non-commercially,

and although the new works must also acknowledge \& be non-commercial.

\section{INTRODUCTION}

Owing to the petroleum based synthetic solid waste accumulation, the developments of bio based materials are of great interest today. Many research groups have been paying their utmost efforts to develop sustainable biocomposite materials with less hazardous effect on the environment. In recent times, the study on the starch based biodegradable nanocomposites films incorporated with cellulose nanocrystal (NCC) reinforcement have progressed significantly (Balakrishnan etal.,2017; Sucaldito, M. R., \& Camacho, D. H., 2017; 
Noshirvani, 2016; Harun et al., 2016; Babaee et al., 2015). New materials from renewable resources have already gained much attention during the last decades due to global need for alternatives to fossil resources (Belgacem, M. N., \& Gandini, A., 2011). PMS/PVA based biocomposite with boric acid as cross linker can be one promising alternative for green environment. Starch (PMS) is a naturally biopolymers with the potential advantages such as low cost, available from renewable resources and capable to replace some synthetic polymers (Martinset al., 2009). However, the inherent disadvantages of starch (high water absorbency, low tensile property), have limited to wider applications. It can be thermoplastic when plasticized with water or other plasticizers-glycerol, sorbitol, and other low-molecular weight polyhydroxy compounds. For developing its properties, starch is being usually blended with other thermoplastic polymers (Chen, Y.et al., 2008). The mechanical properties of starch polymer matrix significantly developed in the presence of natural fillers as reinforcements (Savadekar, N. R. \& Mhaske, S. T., 2012).In addition, PVA exhibits good mechanical and barrier properties and is extremely compatible with starch. It is a water-soluble, nontoxic, flexible and synthetic biodegradable polymer. Furthermore, PVA has the characteristics of ease of preparation, good film formation, strong conglutination, high thermal stability, excellent chemical resistance, good durability, and adhesive properties (Chen, N.et al., 2007). Another report shown that PVA based biodegradable composites have been prepared by the incorporation of natural polymers such as pea starch and cellulose (Chen, Y. et al., 2008). Owing to the versatile characteristics of PVA, researchers have gained attention on the preparation of bio-blend films incorporating PVA and starch (Maria Rapa et al., 2014).Considering the environmental issues, among the various crosslinking agents, boric acid was used due to its excellent crosslinking agent and has no adverse effect on the environment(Yin, Y.et al.,2005). Moreover, boric acid is beneficial to the growth of plants. Therefore, the purpose of this research was to focus on the biodegradability and recyclability nature along with thermochemical and physico-mechanical properties of partially pregelatinized maize starch (PMS) and polyvinyl alcohol (PVA) based composites for cost effective eco-friendly packaging material. So far, no such observation on PMS/PVA based biocomposites incorporated with boric acid have been reported yet.

\section{Experimental Materials AND Methods}

\section{Materials}

White granular partially pregelatinized maize starch (PMS, pharma grade) having particle size between 75-125 $\mu \mathrm{m}$ containing 9\% moisture was collected from Colorcon, USA. Polyvinyl alcohol (PVA) with a molecular weight of 115,000 was purchased from Merck (Schuchardt OHG 85662, Hohenbrum, Germany). Sorbitol and boric acid (BA) used were reagent grade and purchased from Merck (India).

\section{Methods}

\section{Obtainment of PMS/PVA based biocomposite films}

The biocomposite films were prepared by solution casting method. Several formulated films (PMS: PVA: BA; 4:5:0, 4:5:0.5, 4:5:1, 4:5:1.5, 4:5:2; wt \%) were prepared with and without sorbitol. The colloidal suspension of PMS in deionized water was prepared by continuous stirring with a magnetic hot plate at about $70{ }^{\circ} \mathrm{C}$ for $1 \mathrm{~h}$. PVA was dissolved in deionized water by continuous stirring with a magnetic hot plate through heating at about $90{ }^{\circ} \mathrm{C}$ for 2h. The colloidal suspension of PMS, PVA and BA were blended for $2 \mathrm{~h}$ through heating at 
about $85-90{ }^{\circ} \mathrm{C}$ by continuous stirring until the homogeneous mixture obtained. Sorbitol (1 $\%$ by $\mathrm{v} / \mathrm{v}$ ), a plasticizer was added to the resultant mixture during blending process after 1.5h stirring. Finally, the biocomposite films were prepared by solution casting on a silicon paper coated glass plate, dried with the relative humidity $(\mathrm{RH})$ at approximately $50 \%$ in the room temperature and removed from the plate for characterization.

\section{Fourier Transform Infrared (FTIR) spectroscopy}

FT-IR spectra of the biocomposite film samples were recorded on a PerkinElmer spectrophotometer. The spectrophotometer was equipped with an attenuated total reflectance (ATR) accessory with a germanium crystal. The spectral resolution was $4 \mathrm{~cm}^{-1}$ with a scanning range from $4000-400 \mathrm{~cm}^{-1}$.

\section{Differential Scanning Calorimetry (DSC)}

DSC analysis was performed using a PerkinElmer DSC-7 system under nitrogen atmosphere. The measurements were performed while heating the samples $(5-10 \mathrm{mg})$ at a rate of $10^{\circ} \mathrm{C} / \mathrm{min}$ within the temperature range of $0-400{ }^{\circ} \mathrm{C}$.

\section{Thermo gravimetric Analysis (TGA)}

TGA analysis was performed using a Thermo gravimetric analyzer (model TGA-50, Shimadzu, Japan) under nitrogen atmosphere. The measurement was performed while heating the samples inside a closed crucible at a rate of $10{ }^{\circ} \mathrm{C} / \mathrm{min}$ within the temperature range of $30-600^{\circ} \mathrm{C}$. Nitrogen was used as a purging gas.

\section{Mechanical properties (Tensile strength and percentage of Elongation at break)}

The tensile properties such as, tensile strength (TS) and percentage of elongation at break $(\mathrm{EB} \%)$ of the biocomposite films were measured with a universal testing machine (Hounsfield, model H50 ks 0404, UK) by ASTM D 882-80a (1995a).The determinations were performed at least in triplicate.

\section{Water Solubility measurement}

The water solubility of the biocomposite films was measured by using a modified reported method (Martelli S. M.et al., 2006). Various films having dimension $30 \times 30 \mathrm{~mm} 2$ were dried at $60{ }^{\circ} \mathrm{C}$ for $24 \mathrm{~h}$ in a vacuum oven. The dried films were kept in a desiccators containing silica gel for about half an hour. The conditioned specimens were immersed in $100 \mathrm{~mL}$ deionized water kept in a beaker for $24 \mathrm{~h}$. Each of the films (with an initial weight) were weighed and recorded. After $24 \mathrm{~h}$ soaking in water, each of the films were removed, oven dried and final dried specimens were weighed and recorded. The determinations were performed in triplicate.

\section{Moisture uptake}

The moisture uptake of the biocomposite films was measured by the reported method (Cao, X. et al., 2007). The films having dimension $30 \times 30 \mathrm{~mm}^{2}$ were dried at $60{ }^{\circ} \mathrm{C}$ overnight in a vacuum oven. The dried specimens were kept in a desiccator containing silica gel for 6 hours $(0 \%$ of $\mathrm{RH})$. Each of the samples were weighed initially and recorded. After taking initial weight, each of the specimens was conditioned at room temperature in a desiccator of $98 \%$ $\mathrm{RH}$ (conditioned by saturated $\mathrm{CuSO}_{4} .5 \mathrm{H}_{2} \mathrm{O}$ solution) for seven days. Seven days later, the specimens were removed from desiccator, weighed and recorded. The moisture uptake was determined as the percentage increase in weight after being conditioned for 7 days at $98 \%$ of RH. The determinations were performed in triplicate. 


\section{Biodegradation Test}

The biodegradation test of the several biocomposite samples were performed by soil burial test (Harun et al., 2016). The samples were cut into $30 \times 30 \mathrm{~mm}^{2}$ dimensions, dried, weighed and placed into soil bed under anaerobic condition (approximately 98\% of RH.0.5, 1,2 and 3 months later, the samples were removed from the soil bed respectively and gently washed with distilled water. After drying the samples at $105{ }^{\circ} \mathrm{C}$ for $1 \mathrm{~h}$, the final weight of each specimen were recorded. The degree of soil degradation was measured by the following equation:

Degree of soil degradation $=\left[\left(W_{o}-W_{d}\right) \times 100 \%\right] / W_{o}$

Where $W_{o}$ and $W_{d}$ are the initial and final weight in dried condition (before and after degradation respectively) of the biocomposite sample. The determinations were performed in triplicate.

\section{RESULTS AND DISCUSSION}

\section{FTIR analysis}

The interaction between starch (PMS) and PVA with the incorporation of boric acid as crosslinker through hydrogen bonding is very important factor for biocomposites and the FT-IR spectra enable the interactions to be identified. The spectral changes in peak bandwidth and frequency provide important data for interpretations of hydrogen bonding formation in the biocomposites. The FT-IR spectra of pure PMS, PVA and selected biocomposites are shown in Fig1. The main characteristics peaks in the spectrum of PMS, PVA and several biocomposites are also listed in Table 1.

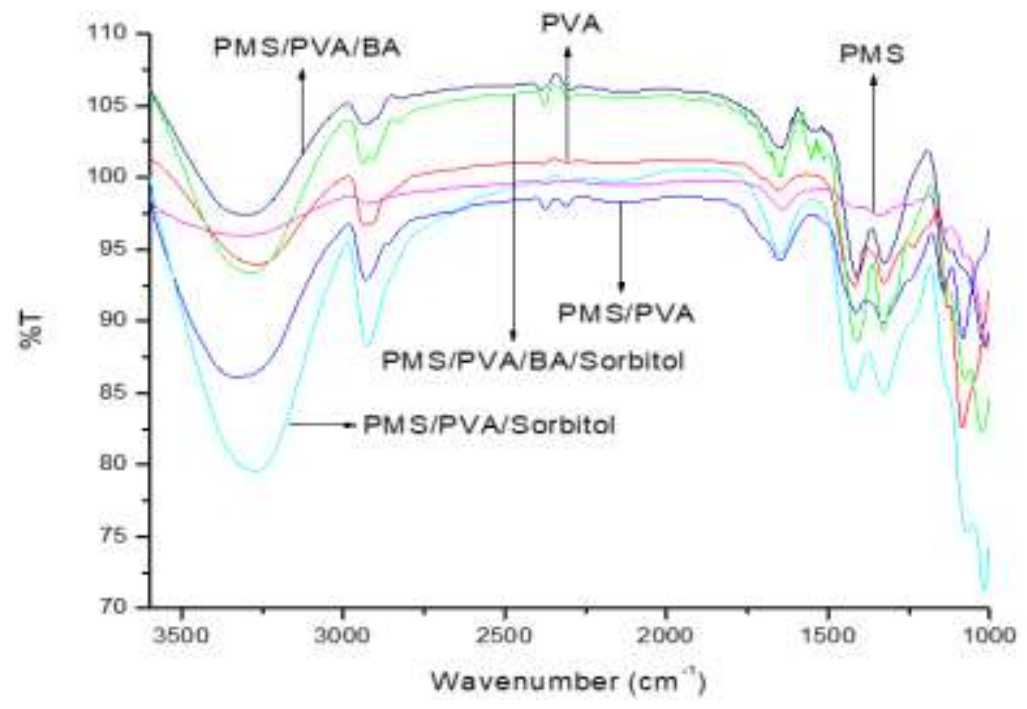

Fig 1: FTIR spectra of starch (PMS), PVA and several PMS/PVA based biocomposite

In the FT-IR spectrum of the unplasticized PMS/PVA/BA based biocomposite, a characteristic peak was observed at $3311 \mathrm{~cm}^{-1}$; due to the presence of intermolecular and intramolecular hydrogen-bonded $-\mathrm{OH}$ groups. The hydrogen-bonded $-\mathrm{OH}$ absorption peak of PMS $\left(3344 \mathrm{~cm}^{-1}\right)$ slightly decreased to $3311 \mathrm{~cm}^{-1}$ in biocomposite; which indicates that hydrogen bonded-OH group of PMS was more strong by boric acid as cross-linker. A sharp 
band was observed at $2941 \mathrm{~cm}^{-1}$; indicating the presence of aliphatic C-H stretching vibrations that was shifted to higher value than that of PMS and PVA. Another peak was found at $1647 \mathrm{~cm}^{-}$ ${ }^{1}$; indicating bending vibration of the hydrogen bonding -OH group that was nearto PMS and PVA. However, the FT-IR spectrum of the sorbitol plasticized PMS/PVA/BA based biocomposite, a characteristic broad band was observed at $3275 \mathrm{~cm}^{-1}$; due to the presence of intermolecular and intramolecular hydrogen-bonded - $\mathrm{OH}$ groups. The hydrogen-bonded $-\mathrm{OH}$ absorption peaks of PMS $\left(3344 \mathrm{~cm}^{-1}\right)$ and PVA $\left(3292 \mathrm{~cm}^{-1}\right)$ significantly decreased to $3275 \mathrm{~cm}^{-1}$ in biocomposite; which indicated that hydrogen bonding took place between PMS and PVA by boric acid as cross-linker. This result was similar with the previous published report (Wolkers et al., 2004; Yin, Y.et al., 2005; Sreedhar et al., 2005).

Table 1: Summary of the FTIR results

\begin{tabular}{|l|l|l|l|l|l|l|}
\hline Functional group & $\begin{array}{l}\text { PMS } \\
\left(\mathrm{cm}^{-1}\right)\end{array}$ & $\begin{array}{l}\text { PVA } \\
\left(\mathrm{cm}^{-2}\right)\end{array}$ & $\begin{array}{l}\text { PMS/PVA } \\
\left(\mathrm{cm}^{-1}\right)\end{array}$ & $\begin{array}{l}\text { PMS/PVA/S } \\
\text { orbitol }\left(\mathrm{cm}^{-1}\right)\end{array}$ & $\begin{array}{l}\text { PMS/PVA } \\
\text { /BA }\left(\mathrm{cm}^{-1}\right)\end{array}$ & $\begin{array}{l}\text { PMS/PVA/BA/ } \\
\text { Sorbitol }\left(\mathrm{cm}^{-1}\right)\end{array}$ \\
\hline OH stretching & 3344 & 3292 & 3327 & 3270 & 3311 & 3275 \\
\hline C-Hstretching & 2924 & 2935 & 2929 & 2921 & 2941 & 2933 \\
\hline Bound water & 1641 & 1653 & 1649 & 1649 & 1647 & 1647 \\
\hline Vibrations associated to & $1413 / 1340$ & - & $1416 / 1330$ & $1423 / 1326$ & $1410 / 1325$ & $1415 / 1330$ \\
\hline C-Ostretching of C-O-C & 1002 & 1080 & 1083 & $1070 / 1017$ & 1010 & $1080 / 1023$ \\
\hline C-Ostretching of C-O-H & 1147 & 1130 & 1143 & - & 1135 & 1141 \\
\hline
\end{tabular}

A sharp band was observed at $2933 \mathrm{~cm}^{-1}$; indicating the presence of aliphatic $\mathrm{C}-\mathrm{H}$ stretching vibrations that more or less similar with PMS and PVA. Another peak was found at 1647 $\mathrm{cm}^{-1}$; indicating bending vibration of the hydrogen bonding -OH group that of nearto PMS and PVA. Two peaks were found at 1415 and $1330 \mathrm{~cm}^{-1}$; which was attributed to the combination frequencies of $-\mathrm{CH}$ and $-\mathrm{OH}$. The single $\mathrm{C}-\mathrm{O}$ stretching of $\mathrm{C}-\mathrm{O}-\mathrm{C}$ group in PMS and PVA transform into double peaks at 1080 and $1023 \mathrm{~cm}^{-1}$ with the addition of sorbitol plasticizer in composite samples (Yoon et al., 2006a). The changes in FT-IR spectrum of other biocomposites are shown in Table 1.

\section{Differential Scanning Calorimetry (DSC) Analysis}

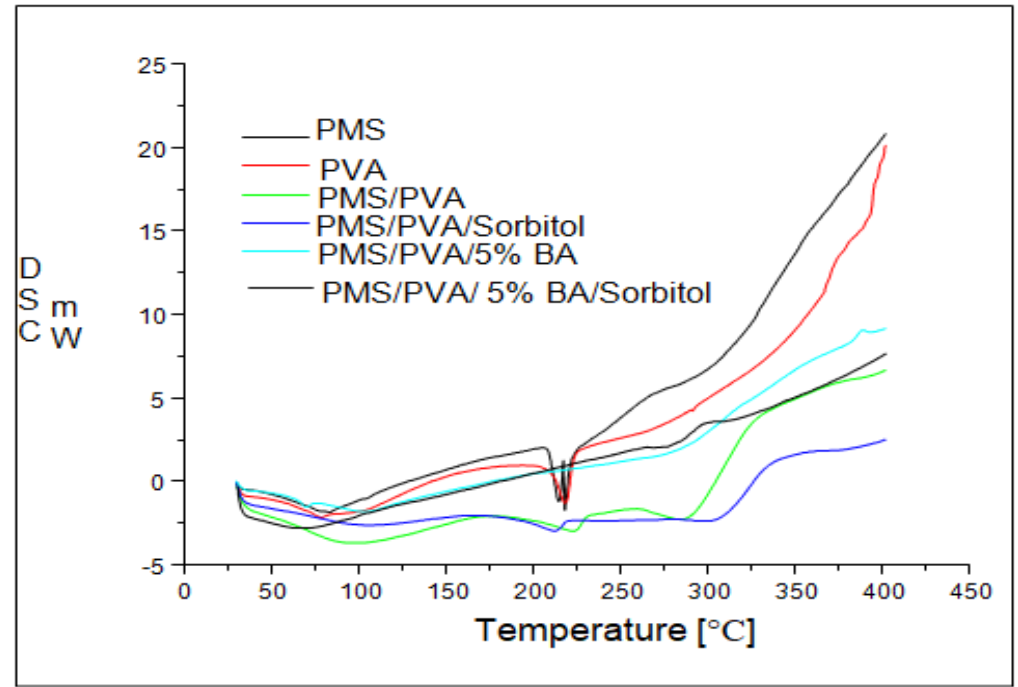

Fig 2: DSC thermograms of starch (PMS), PVA and several PMS/PVA based biocomposite 
The DSC thermo grams of the PMS, PVA and selective PMS/PVA/BA based biocomposite samples shown in Fig 2. PMS and PVA exhibit sharp endothermic peaks (typically of a semi crystalline polymeric system) that have been associated with the melting of crystalline PMS and PVA domains reorganization. The main thermal parameters of PMS, PVA and biocomposite samples are listed in Table 2.

The DSC thermograms of PMS showed a broad endothermic peak at $84{ }^{\circ} \mathrm{C}$, indicates the $T_{8}$ of PMS; as well as the crystallization transition. Another strong and narrow endothermic peak was observed at $218.26{ }^{\circ} \mathrm{C}$; which represented the melting temperature $T_{m}$. For pure PVA, a broad endothermic peak at around $77^{\circ} \mathrm{C}$ was found on the thermograms indicated the $T_{g}$ of PVA; as well as the crystallization transition. Another strong and narrow endothermic peak was observed at $210^{\circ} \mathrm{C}$; which represented the melting temperature $T_{m}$ of PVA. In the DSC thermograms of unplasticized PMS/PVA/BA based biocomposite, a broad peak at around $75^{\circ} \mathrm{C}$ was found on the thermograms that indicated the $T_{g}$ of biocomposite and no clear $T_{m}$ was observed. For sorbitol plasticized PMS/PVA/BA based biocomposite, a broad peak at around $70{ }^{\circ} \mathrm{C}$ was found on the thermograms that obviously indicated the $T_{g}$ of biocomposite.

Table 2: Tg and Tm of PMS, PVA and several PMS/PVA based biocomposites

\begin{tabular}{|l|l|l|}
\hline Sample/Composites & $\mathrm{T}_{\mathrm{g}}$ & $\mathrm{T}_{\mathrm{m}}$ \\
\hline PMS & 84 & 218.26 \\
\hline PVA & 77 & 210 \\
\hline PMS/PVA & 102 & None \\
\hline Sorbitol plasticized PMS/PVA & 95 & none \\
\hline PMS/PVA/ BA & 75 & None \\
\hline Sorbitol plasticized & 70 & None \\
\hline
\end{tabular}

Moreover, addition of sorbitol plasticizer in composite, it was found that $T_{8}$ decreased (which is lower than that of PMS and PVA) significantly and also found absent of clear $T_{m}$. This may be due to the loss of $-\mathrm{OH}$ groups that exist in PMS and PVA because of crosslinking. Cross linked composites prepared by containing sorbitol as a plasticizer exhibited lower $T_{g}$. These result might be attributed because of plasticizers reduce the $T_{g}$ value of polymers. These results were similar with the report that observed the effect of plasticizers in different polymer blend composites by investigating the degree of changes in $T_{g}$ (Yoon et al., 2006a; Sreedhar et al., 2006.

\section{Thermogravimetric Analysis (TGA)}

The TGA thermograms of pure PMS, PVA and several biocomposites shown in Fig 3. In the TGA thermograms of pure PMS, only three weight loss steps were observed. The initial weight loss (11.47\%) occurred within the temperature range $40.0-201.12{ }^{\circ} \mathrm{C}$; due to the elimination of moisture and water. Steps 2 and 3 were the degradation step. The maximum degradation (50.28\%) was observed on step 2 in the temperature range $201.12-402.95{ }^{\circ} \mathrm{C}$; with most prominent degradation at $310^{\circ} \mathrm{C}$ due to the characteristic decomposition of PMS (cracking of PMS) (Muller et al., 1998). Some gases such as $\mathrm{CO}_{2}, \mathrm{CO}, \mathrm{H}_{2} \mathrm{O}$ and other small volatiles are released during this stage along with carbonaceous residue formation (Zhou, $X$ et al., 2009). The last stage took place between $488.42-599.62^{\circ} \mathrm{C}$ and corresponds to the decomposition of previously formed residue (Muller et al., 1998).In the TGA thermograms of pure PVA, three weight loss steps were observed. 


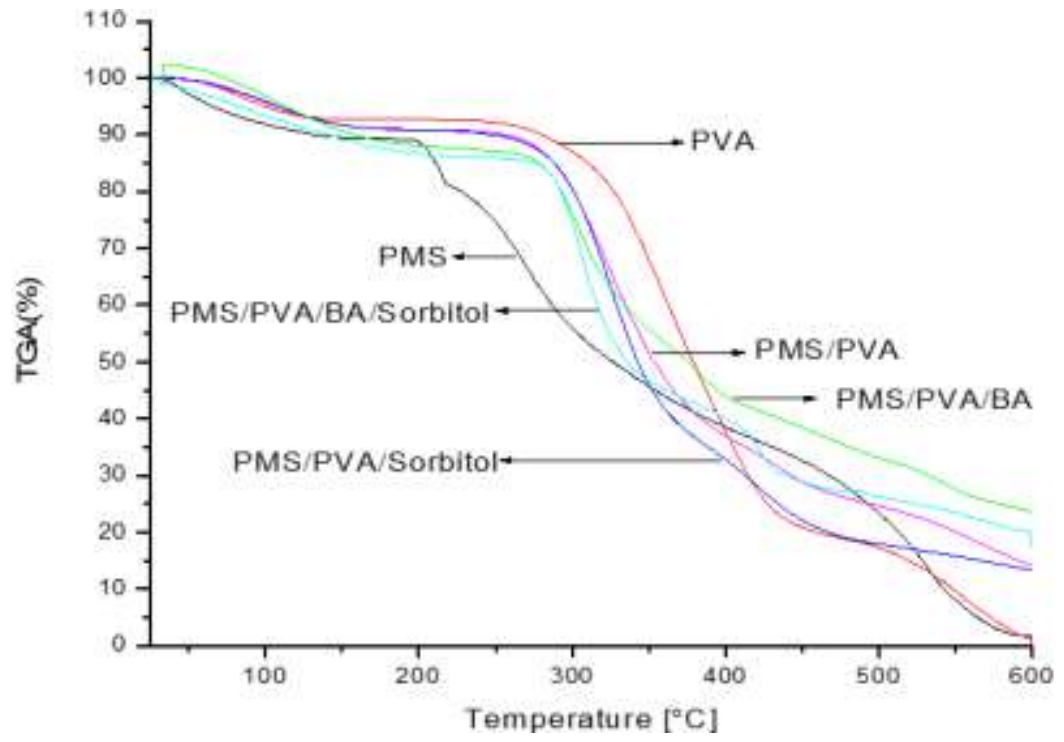

Fig 3: TGA thermograms of starch (PMS), PVA and several PMS/PVA based biocomposites

The initial weight loss $(10.43 \%)$ within the temperature range $50.0-288.83{ }^{\circ} \mathrm{C}$ was associated with the elimination of moisture and water. Steps 2 and 3 were the degradation step. In step 2, the maximum degradation (74.91\%) was observed in the temperature range 288.83-525.00 ${ }^{\circ} \mathrm{C}$ and was due to the characteristic decomposition of PVA. In degradation step 3, from 525to $599.34{ }^{\circ} \mathrm{C}$ a slow degradation of $13.41 \%$ was observed, due to the characteristic decomposition of PVA (cracking of PVA). Afterwards, the curve becomes flat which indicated that only the inorganic residues were left (Zhou, $X$ et al., 2009). The TGA thermograms of sorbitol plasticized and unplasticized PMS/PVA with or without BA based biocomposite, three weight loss steps were observed. It was observed that both sorbitol plasticized and unplasticized PMS/PVA/BA biocomposite samples showed similar weight loss in different steps of degradation, and neither completely resembled with PMS or PVA; although the unplasticized sample maintained its weight for longer temperature range. However, the PMS/PVA/BA based biocomposites experienced the overall lowest thermal degradation; therefore, more thermally stable. This result supported by the report (Yin, Y. et al., 2005; Sreedhar et al., 2005) that might be due to the crosslinking through hydrogen bonding between PMS and PVA by BA as cross-linker. This result again found the resemblance with FT-IR and DSC analysis.

\section{Tensile properties (Tensile Strength and percentage of Elongation at Break)}

Cross linking agents and plasticizers often tend to have opposing effects on the tensile properties of the composites. Generally, the tensile strength increased and the elongation at break decreased as the percentage of cross linking agent increased. The results are often opposite when plasticizers are increased (Sreedhar et al., 2006). Fig 4a shows the tensile strength (TS) and percentage of elongation at break (EB \%) of unplasticized PMS/PVA based biocomposites containing various amounts of BA. It has been observed that, the tensile strength showed an upward trend; and then eventually fell off with increasing boric acid. The reason can be attributed due to the hydrogen bonds that were taking place between PMS and PVA in presence of BA. This result was also supported by the report that stated the hydrogen bonding occurs between starch and PVA by boric acid (Yin, Y. et 
al., 2005) and borax (Sreedhar et al., 2005) as cross-linker. Similar results were also observed on the FTIR, DSC and TGA analysis as well. For elongation, the opposite scenario was found, as EB (\%) first decreased and then started increasing again. The TS value was observed 17.2, 33.5, 38.1, 33.5 and 21.8 $\mathrm{MPa}$; while $\mathrm{EB}$ (\%) was 9.6, 6.4, 5.9, 6.4 and $8.5 \%$ for unplasticized biocomposites containing $0,5,10,15$ and $20 \%$ boric acid respectively. Fig $4 \mathrm{~b}$ shows the tensile strength (TS) and percentage of elongation at break $(\mathrm{EB} \%)$ of sorbitol plasticized PMS/PVA based biocomposites containing various amounts of boric acid.

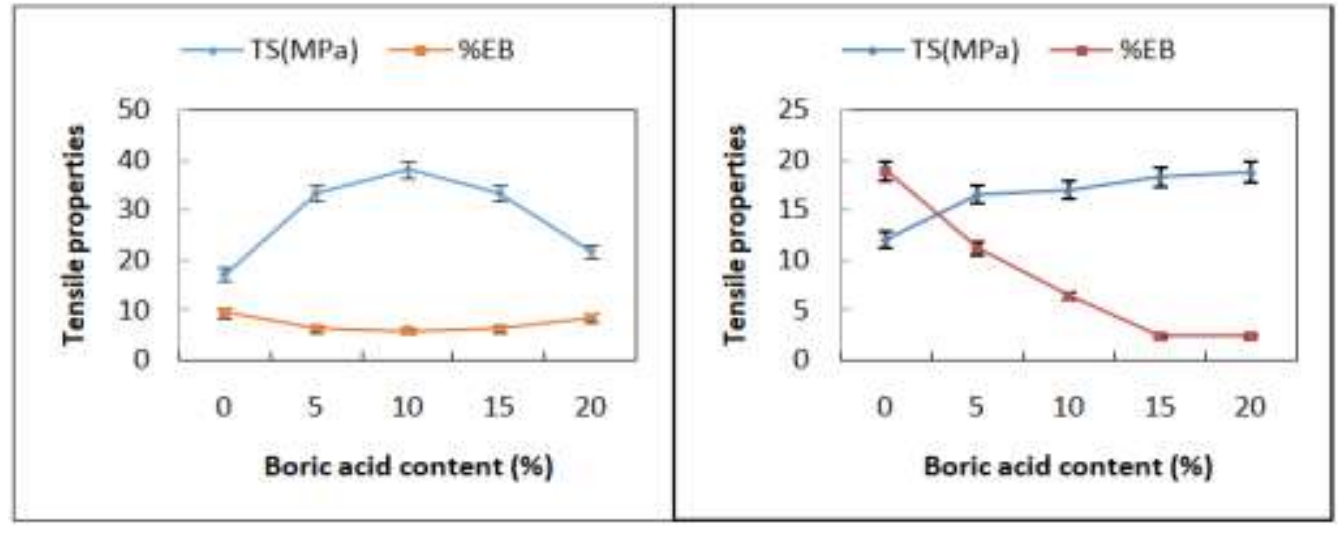

4a

$4 \mathbf{b}$

Fig 4: Tensile strength (TS) and percentage of elongation at break (EB \%) of unplasticized PMS/PVA (4a) and sorbitol plasticized PMS/PVA (4b) based bio-composite as a function of BA content

It has been also observed that, the tensile strength increased with increasing boric acid content, while percentage of EB kept falling off. TS was observed to be 12.1, 16.6, 17.0, 18.3 and 18.8 MPa; while percentage of EB was found to be 18.9, 11.2, 6.4, 2.4 and $2.4 \%$ for samples containing $0,5,10,15$ and $20 \%$ boric acid respectively.

\section{Water solubility}

The water solubility of various biocomposites is shown in Fig 5a. It has been observed that the solubility of both unplasticized and sorbitol plasticized PMS/PVA biocomposites increased with increasing BA content.

The water solubility was 36.9, 43.9, 61.0, 65.1 and $69.5 \%$ for unplasticized composites containing $0,5,10,15$ and $20 \%$ boric acid respectively; whereas it was 42.9, 49.5, 62.2, 66.9 and $100 \%$ for sorbitol plasticized composites containing $0,5,10,15$ and $20 \%$ boric acid respectively. It was also observed that $5 \%$ BA containing biocomposites exhibited relatively low water solubility than that of other composites. This result may be due to strong hydrogen bonding takes place between PMS and PVA when 5\% BA was used rather than higher BA content.

This finding is similar to citric acid where carboxyl groups formed strong hydrogen bonds with the hydroxyl groups on starch, thus improving the interaction between the molecules and decreasing the water sensitivity (Spinella et al., 2016). Plasticization was also boosted the water solubility. 


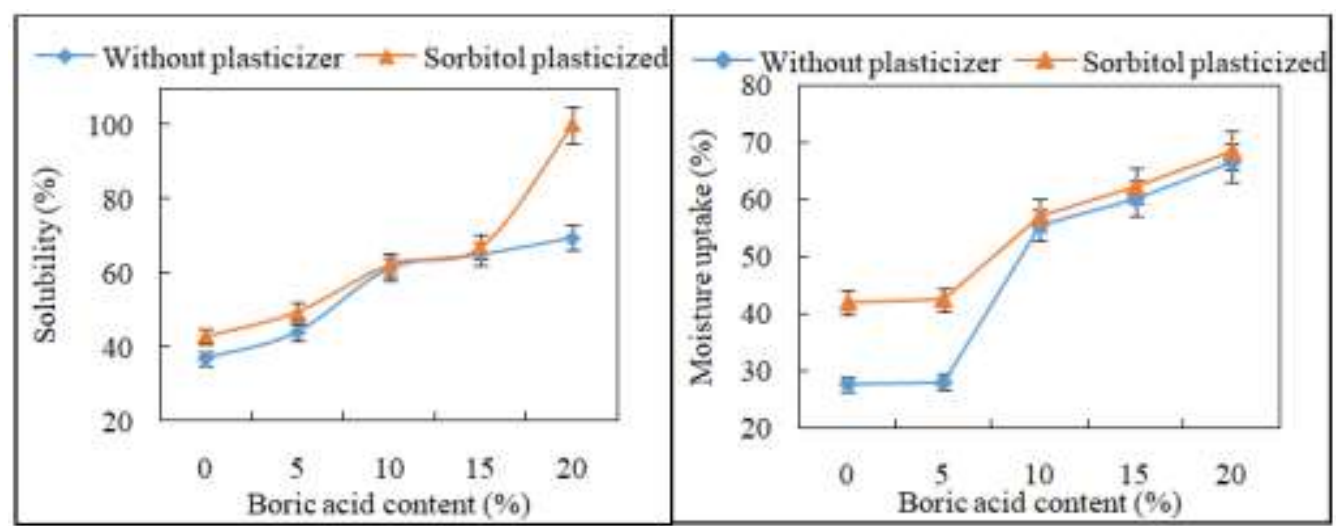

5a

5b

Fig. 5: The water solubility (5a) and moisture uptake (5b) of unplasticized PMS/PVA and sorbitol plasticized PMS/PVA based bio-composite as a function of the variation of boric acid (BA) content

\section{Moisture uptake}

Because of the strong hydrophilicity of PMS molecules, a strong PMS film showed high water absorbency. Cross linking of PMS macromolecules reinforces the intermolecular binding by introducing covalent bonds that supplement natural intermolecular hydrogen bonds so as to improve the water resistibility (Krumova et al., 2000). Since pure PVA and PMS is highly sensitive to moisture, any decrease or increase in moisture sensitivity for the biocomposites is very significant. From the Fig $5 b$, for both sorbitol plasticized and unplasticized biocomposites, the moisture uptake increased with increasing the amount of BA. Plasticized samples showed more moisture uptake than their unplasticized counterparts. Since sorbitol exhibit extremely hydrophilicity, introducing it in the composites boosted water uptake greatly. The moisture up take was $25.6,28.0,55.5,60.2$ and $66.5 \%$ for unplasticized composites; whereas it was $41.9,42.4,57.2,62.3$ and $68.5 \%$ for sorbitol plasticized composites containing $0,5,10,15$ and $20 \%$ boric acid respectively. Like that water solubility, for plasticized biocomposite containing $5 \%$ BA showed a low moisture sensitivity than that of other composites, however, the unplasticized biocomposite had relatively lower percentage of moisture uptake than that of plasticized biocomposite. The lower percentage of moisture uptake in composite than that of other composites once more proved that hydrogen bonding takes place between PMS and PVA. (Gohil et al., 2006). Thus, the moisture sensitivity of PMS/PVA based biocomposite greatly influence by the incorporation of BA content.

\section{Biodegradation test}

The biodegradation of several composites are shown in Fig 6. It has been observed that the degradation rate increased with increasing time. The findings revealed that the biodegradation rate after 3 months was 70 and $72 \%$ for unplasticized PMS/PVA/BA and sorbitol plasticized PMS/PVA/BA composites respectively. This result was supported with the findings reported by Bastioli et al. research group (Harunet al., 2016; Tudorachi et al., 2000). Slow degradation results of biocomposites may be attributed due to cross linking occur through hydrogen bonding between PMS and PVA incorporated with BA crosslinker. In addition, the degradable data for composites without BA were not recorded after2 months due to the cracking and thus dispersal in soil. The biodegradability results of pure 
PMS and PVA were not shown as they exhibited quick degradation. Thus, this finding was also analogous with all results described in this article.

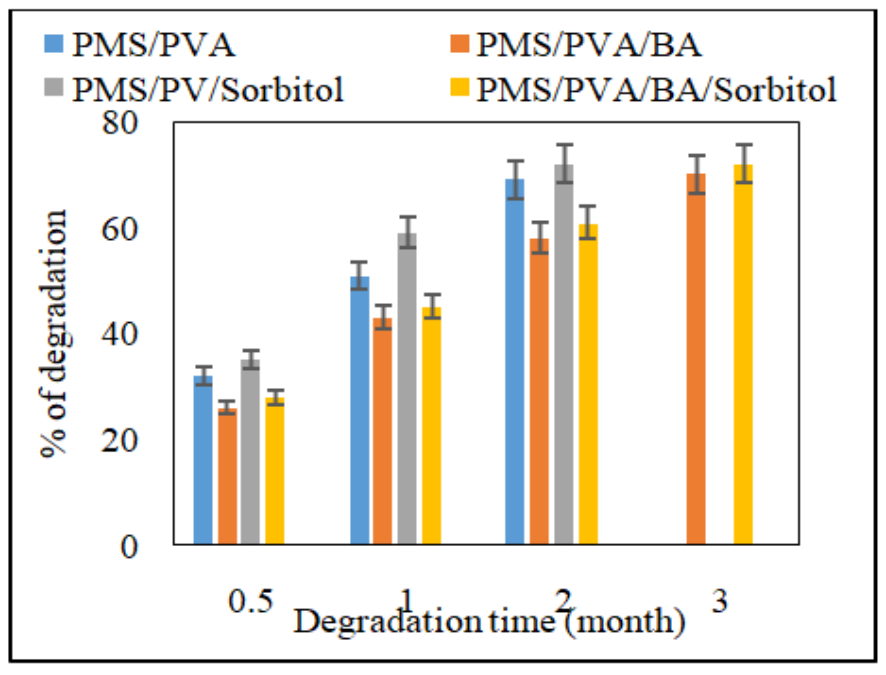

Fig 6: Biodegradation (\%) versus time (Month) for several bio-composites

\section{CONCLUSION}

As a result of the increasing of synthetic polymer based solid waste accumulation and considering the environmental issues, development of new biodegradable materials from renewable sources have gained great attention of researchers. However, biopolymers cannot merely be used and should be incorporated with other biodegradable materials to improve their physico-mechanical properties as a sustainable product. Although the properties of variety of starch/PVA blends have been investigated, innovative sustainable biocomposite materials are highly needed for green environment in commercial scale. In this sense, several PMS/PVA/BA based biocomposites have been investigated in different mass ratio. While investigating the chemical, thermal and physico-mechanical properties along with biodegradability nature; different techniques were applied to characterize the biocomposites. The FT-IR, DSC and TGA results revealed that the hydrogen bonding takes place between PMS and PVA through crosslinking by boric acid. The cross linked composites also shown enhanced mechanical properties and thus thermally stable (reduction of Tg) than that of neat PMS and PVA. In addition, sorbitol plasticization lowers the mechanical strength but confirms the flexible (free of cracking) biocomposite. However, using of sorbitol, composites exhibited the higher water solubility and moisture uptake. In addition, the composite was also investigated for biodegradability and found it biodegradable. Thus, the results revealed that sorbitol plasticized PMS/PVA composite incorporated with 5\% BA showed comparatively lower moisture sensitivity, moderate water solubility, optimum mechanical properties and good thermal stability than that of other composites. Based on the properties stated in this article, sorbitol plasticized PMS/PVA/BA (5\%) blend was optimized as pliable and sustainable biocomposite materials for packaging application. So far, no specific research on sorbitol plasticized PMS/PVA/BA based biocomposites has been reported yet. Therefore, based on this report and review of related works, sorbitol plasticized PMS/PVA/BA based biocomposite can be alternative approach as an innovative eco-friendly packaging material. 


\section{ACKNOWLEDGEMENT}

The authors are highly grateful to Prof. Dr. Md. Kamruzzaman (Department of Applied Chemistry and Chemical Engineering, Dhaka University) for FT-IR, TGA and DSC analytical facilities. And no fund was received to carry out this research.

\section{REFERENCES}

Babaee, M., Jonoobi, M., Hamzeh, Y., \& Ashori, A. (2015). Biodegradability and mechanical properties of reinforced starch nanocomposites using cellulose nanofibers. Carbohydrate polymers, 132, 1-8.

Balakrishnan, P., Sreekala, M. S., Kunaver, M., Huskić, M., \& Thomas, S. (2017). Morphology, transport characteristics and viscoelastic polymer chain confinement in nanocomposites based on thermoplastic potato starch and cellulose nanofibers from pineapple leaf. Carbohydrate Polymers, 169, 176-188.

Belgacem, M. N., \& Gandini, A. (Eds.). (2011). Monomers, polymers and composites from renewable resources. Elsevier.

Cao, X., Chen, Y., P. R., \& Huneault, M. A (2007). Preparation and properties of plasticized starch/multiwalled carbon nanotubes composites. Journal of Applied Polymer Science, 106(2), 1431-1437.

Chen, N., Li, L., \& Wang, Q. (2007). New technology for thermal processing of poly (vinyl alcohol). Plastics, Rubber and Composites, 36(7-8), 283-290.

Chen, Y., Cao, X., Chang, P. R., \& Huneault, M. A (2008). Comparative study on the films of poly (vinyl alcohol)/pea starch nanocrystals and poly (vinyl alcohol)/native pea starch. Carbohydrate Polymers, 73, 8-17.

Gohil, J. M., Bhattacharya, A., \& Ray, P. (2006). Studies on the crosslinking of poly (vinyl alcohol). Journal of polymer research, 13(2), 161-169.

Harun- or- Rashid MD, Rahaman S, Enamul Kabir S, Khan MA (2016). Effect of hydrochloric acid on the properties of biodegradable packaging materials of carboxymethylcellulose/poly (vinyl alcohol) blends. Journal of Applied Polymer Science, 133(2).

Krumova, M. Lopez, D., R., Mijangos, C., Perena, J.M (2000). Effect of crosslinking on the mechanical and thermal properties of poly (vinyl alcohol). Polymer, 41, 9265-9271.

Maria Rapa, Elena Gruso, Petruta Stoica, Mihaela Andreica (2014). Polyvinyl alcohol and starch blends: properties and biodegradation behavior. Journal of Environmental and Research Protection, Volume 11, Issue 1.

Martelli S. M., Geovana M., Paes S. S., Cristhiane G. Jo ao, B. L (2006). LWT—Food Sci.Technol, 39,292.

Martins, M. G. I., Magina, S. P., Oliveira, L., Freire, C. S. R., Silvestre, A. J. D., Neto, C.P., et al (2009). New biocomposites based on thermoplastic starch and bacterial cellulose. Composites Science and Technology, 69(13), 2163-2168.

Muller, R.J.; Witt, U.; Rantze, E.; Deckwer, W.D (1998). Architecture of biodegradable copolyesters containing aromatic constituents. Polym. Degrad, 59, 203-208.

Noshirvani, N., Ghanbarzadeh, B., Fasihi, H., \& Almasi, H. (2016). Starch-PVA nanocomposite film incorporated with cellulose nanocrystals and MMT: a comparative study. International journal of food engineering, 12(1), 37-48.

Savadekar, N. R., \& Mhaske, S. T (2012). Synthesis of nano cellulose fibers and effect on thermoplastics starch based films. Carbohydrate Polymers, 89(1), 146-151.

Spinella, S., Maiorana, A., Qian, Q., Dawson, N. J., Hepworth, V., McCallum, S. A., \& Gross, R. A. (2016). Concurrent cellulose hydrolysis and esterification to prepare a surface-modified cellulose nanocrystal decorated with carboxylic acid moieties. ACS Sustainable Chemistry \& Engineering, 4(3), 1538-1550. 
Sreedhar, B., Chattopadhyay, D.K., Karunakar, M.S.H., \& Sastry, A.R.K (2006). Thermal and surface characterization of plasticized starch polyvinyl alcohol blends crosslinked with epichlorohydrin. Journal of Applied Polymer Science, 101, 25-34.

Sreedhar, B., Sairam, M., Chattopadhyay, D. K., Rathnam, P. A., \& Rao, D. V. (2005). Thermal, mechanical, and surface characterization of starch-poly (vinyl alcohol) blends and boraxcrosslinked films. Journal of Applied Polymer Science, 96(4), 1313-1322.

Sucaldito, M. R., \& Camacho, D. H. (2017). Characteristics of unique HBr-hydrolyzed cellulose nanocrystals from freshwater green algae (Cladophora rupestris) and its reinforcement in starchbased film. Carbohydrate Polymers, 169, 315-323.

Tudorachi, N., Cascaval, C. N., Rusu, M., \& Pruteanu, M. (2000). Testing of polyvinyl alcohol and starch mixtures as biodegradable polymeric materials. Polymer Testing, 19(7), 785-799.

Wolkers, W. F., Oliver, A. E., Tablin, F., \& Crowe, J. H. (2004). A Fourier-transform infrared spectroscopy study of sugar glasses. Carbohydrate research, 339(6), 1077-1085.

Yin, Y., Li, J., Liu, Y., \& Li, Z. (2005). Starch cross linked with poly (vinyl alcohol) by boric acid. Journal of Applied Polymer Science, 96(4), 1394-1397.

Yoon, S.D., Chough, S.H., \& Park, H.R (2006a). Properties of starch-based blend films using citric acid as additive. Journal of Applied Polymer Science, 100, 2554-2560.

Zhou, X. Y., Jia, D. M., Cui, Y. F., \& Xie, D. (2009). Kinetics analysis of thermal degradation reaction of PVA and PVA/starch blends. Journal of Reinforced Plastics and Composites, 28(22), 2771-2780. 